\title{
Increased numbers of IgG-containing cells in rectal lamina propria of patients with ankylosing spondylitis
}

\author{
MALCOLMA. STODELL, ROBIN C. BUTLER, VIVIANAA. ZEMELMAN, \\ KRISTIN HENRY, AND DERRICK A. BREWERTON \\ From the Departments of Rheumatology and Histopathology, Westminster Hospital Medical School, London \\ SW1P 2AP
}

SUMMARY Using an indirect immunoperoxidase technique we found the numbers of IgG-containing cells in the rectal lamina propria to be increased in patients with ankylosing spondylitis compared with controls, but not in patients with acute anterior uveitis or rheumatoid arthritis, or in the first-degree relatives of patients with ankylosing spondylitis. No differences between diagnostic groups were detected in the numbers of cells containing $\operatorname{IgA}, \operatorname{IgM}, \operatorname{IgD}$, or $\operatorname{IgE}$. The total numbers of plasma cells in the rectal lamina propria were not significantly increased. Similar increases of IgG-containing cells were not found in the duodenal lamina propria of patients with ankylosing spondylitis.

Despite much recent discussion of the concept of reactive arthritis, and of the association of ankylosing spondylitis with diseases of the gut and genitourinary tract, there is no firm evidence that gut disorders are directly involved in the aetiology of ankylosing spondylitis. Most patients with ankylosing spondylitis (or rheumatoid arthritis) deny that their rheumatic symptoms are influenced by intercurrent infections of the lung, pharynx, gut, or genitourinary tract. Nevertheless, many rheumatologists believe that occult infection at these sites may precipitate the onset and the subsequent exacerbations of various forms of chronic arthritis, including ankylosing spondylitis, and possibly also acute anterior uveitis. On the basis of this hypothesis it was decided to study rectal and duodenal biopsies of patients with ankylosing spondylitis and with acute anterior uveitis in a search for either infective agents or evidence of an immunological reaction suggestive of their presence.

Acute anterior uveitis is clinically related to ankylosing spondylitis and shares with it a common genetic association with HLA-B27. Because it is an acute disorder with an abrupt, painful onset, acute anterior uveitis can be investigated during attacks shortly after the onset of symptoms. For comparison with

Accepted for publication 21 June 1983.

Correspondence to Professor D. A. Brewerton, Department of Rheumatology, Westminster Hospital, Horseferry Road, London SW1P 2AP. spondylitis and uveitis the following diagnostic groups were chosen: rheumatoid arthritis, firstdegree relatives of patients with spondylitis, irritable bowel syndrome (as controls for rectal biopsies), and patients with minor dyspeptic symptoms (as controls for duodenal biopsies).

\section{Patients and methods}

The study included 18 patients with ankylosing spondylitis, 11 patients without rheumatic disease during attacks of acute anterior uveitis, 12 patients with rheumatoid arthritis, 4 first-degree relatives of spondylitic patients, 9 patients with irritable bowel syndrome, and 5 patients with minor dyspeptic symptoms.

Apart from the 2 control groups no subjects gave a history of relevant gastrointestinal disease and none had experienced gastrointestinal symptoms during the previous 6 months. Also excluded were: subjects with a history of genitourinary symptoms or disease, subjects with a history of infection at any site during the previous 3 months, subjects believed to be homosexual (after direct questioning), subjects who had used suppositories in the previous 12 months, and subjects who had ever been treated with radiotherapy, steroids or immunosuppressive drugs.

The subjects were aged 20-60 years. In the clinical groups the mean ages were: spondylitis 29.7 years, 
uveitis 31.8 years, rheumatoid arthritis 44.9 years, relatives $35 \cdot 7$ years, irritable bowel syndrome $35 \cdot 8$ years and dyspepsia 45.4 years. The sex ratios (men/women) were: spondylitis $13 / 5$, uveitis $7 / 4$, rheumatoid arthritis $5 / 7$, relatives $0 / 4$, irritable bowel syndrome $5 / 4$, dyspepsia $1 / 4$. Oral drugs were excluded in all subjects apart from nonsteroidal antiinflammatory drugs required by 9 patients with spondylitis and by all the patients with rheumatoid arthritis, and penicillamine prescribed in 4 patients with rheumatoid arthritis.

Patients with spondylitis had classical ankylosing spondylitis and satisfied the New York criteria. ${ }^{1}$ Disease activity was assessed clinically by one observer (D.A.B.) as: quiescent, requiring no treatment; apparently active disease controlled by drugs; or clearly active inflammatory disease of the spine, peripheral joints, or eyes. Acute episodes of inflammatory disease of the spine, peripheral joints, or eyes during the preceding 2 months were recorded. Patients with acute anterior uveitis (diagnosed by casualty officers at Moorfields Hospital) all had unilateral, painful inflammation of the anterior chamber of the eye; duodenal and rectal biopsies were performed within 5 weeks of the onset of symptoms. Patients with rheumatoid arthritis had classical or definite disease (New York criteria). ${ }^{2}$ Four asymptomatic relatives of patients with spondylitis volunteered ( 2 daughters, 1 mother, and 1 sister); all had HLA-B27 but no evidence of rheumatic disease. The patients with irritable bowel syndrome had no abnormality on clinical examination or sigmoidoscopy and had a normal barium enema and rectal biopsy. The patients with mild dyspepsia had no abnormality of the oesophagus, stomach, or duodenum on endoscopy. All subjects gave their informed consent to the biopsy procedure, and the project was approved by the Ethical Committees at Westminster Hospital and Moorfields Hospital.

Rectal biopsies were taken via a sigmoidoscope 10 to $15 \mathrm{~cm}$ from the anal margin; the rectal mucosa appeared normal in all cases. Duodenal biopsies were taken from the second part of the duodenum. At the same time as the biopsies other specimens were collected: urine and faeces for an electronmicroscopic search for organisms (Dr R. Bird, London School of Hygiene and Tropical Medicine), blood, tears, cervical secretions, urethral secretions, and duodenal juice for antibodies to chlamydiae and herpes simplex viruses (Professor S. Darougar, Institute of Ophthalmology), blood for antibodies to other viruses (Professor J. R. Pattison, King's College Hospital, London), and blood, cervical secretions, urethral secretions, faeces, and rectal swabs for culture for chlamydiae and herpes simplex viruses (Professor Darougar).
The rectal and duodenal biopsies were fresh when received in the Department of Histopathology. They were immediately divided into 3 parts, of which a small representative sample was frozen and sent for immunofluorescent studies for evidence of chlamydial or herpes simplex infections (Dr J. D. Treharne, Institute of Ophthalmology). Another small sample was fixed in 3\% cacodylate buffered glutaraldehyde for electron microscopical studies $(\mathrm{KH})$. The remainder of the biopsy was routinely processed for light microscopy. Sections were stained with haematoxylin and eosin ( $\mathrm{H}$ and $\mathrm{E})$, elastic van Gieson, methyl green pyronine, Gram's stain, and the high iron diamine/alcian blue (HID/AB) technique for mucins. They were examined blind by one observer (K.H.) for evidence of inflammation or any other abnormality. The methyl green pyronine method was used to assess the numbers of pyroninepositive cells (mainly plasma cells) in standard areas of the lamina propria in the rectal biopsies but not in the duodenal biopsies. Further sections of rectal and duodenal biopsies were studied by an immunocytochemical method using the indirect peroxidase antiperoxidase technique ${ }^{3}$ with appropriate antibody controls. ${ }^{4}$

Rabbit antisera to human $\operatorname{IgG}, \operatorname{IgA}, \operatorname{IgM}, \operatorname{IgD}$, and IgE, swine antirabbit immunoglobulin, normal swine serum and peroxidase-antiperoxidase complex (PAP) were obtained from Dakopatts (Mercia Brocades Ltd). Endogenous peroxidase activity was abolished by treatment of sections with $0.5 \% \mathrm{H}_{2} \mathrm{O}_{2}$ in methanol for 10 minutes. All sections were pretreated with $0.1 \%$ trypsin (Sigma) in $0.1 \% \mathrm{CaCl}_{2}$ (pH 7.8) for 30 minutes, and with normal swine serum for 10 minutes. Primary rabbit antisera were used at a dilution of $1: 200$; swine antirabbit antiserum at a dilution of $1: 20$, and PAP at 1:50. The peroxidase reaction was developed with $3,3^{\prime}$ diaminobenzidine tetrahydrochloride (Sigma) and hydrogen peroxide.

Biopsies from subjects of different diagnostic categories were randomly mixed in batches, both for staining and for counting, but at the time of counting the observer did not know the diagnostic categories. On average $286 \mathrm{IgA}$ cells were counted in each biopsy, and for other immunoglobulin classes equivalent numbers of cells were counted in areas of similar size. For each biopsy section the area of lamina propria was measured by projection on a screen with $\times 150$ magnification, by means of a Kontron MOP-AMO-2 graphic tablet with computer interface. The number of cells was expressed per unit area - equivalent to $0.45 \mathrm{~mm}^{2}$ of lamina propria.

In the statistical analysis the 4 patient groups were compared with each other by the Kruskal-Wallis test. The results in each patient group were compared with 
Table 1 Mean numbers of immunoglobulin-containing cells per standard area of rectal lamina propria

\begin{tabular}{lccccc}
\hline Cells $/ 0.45 \mathrm{~mm}^{2}$ & $\begin{array}{l}\text { Spondylitis } \\
(n=18)\end{array}$ & $\begin{array}{l}\text { Uveitis } \\
(n=11)\end{array}$ & $\begin{array}{l}\text { Rheumatoid } \\
(n=12)\end{array}$ & $\begin{array}{l}\text { Relatives } \\
(n=4)\end{array}$ & $\begin{array}{l}\text { Irritable bowel } \\
\text { syndrome } \\
(n=9)\end{array}$ \\
\hline IgA & 488 & 393 & 339 & 390 & 443 \\
IgG & $399^{*}$ & 248 & 235 & 228 & 186 \\
IgM & 54 & 34 & 32 & 19 & 72 \\
IgD & 1 & 0 & 0 & 25 & 31 \\
IgE & 46 & 42 & 30 & & 0 \\
\hline
\end{tabular}

Spondylitis, uveitis, rheumatoid, and irritable bowel syndrome $p<0 \cdot 001$ (Kruskal-Wallis test); spondylitis versus irritable bowel syndrome, p $<0.005$ (Mann-Whitney U test).

controls by the Mann-Whitney $U$ test, and the Spearman's rank test was used for within-group correlations.

\section{Results}

Sections from rectal and duodenal biopsies stained with haematoxylin and eosin showed minor nonspecific inflammatory changes in a high proportion of patients, which did not differ in frequency between the diagnostic groups. Three patients had more severe infammatory changes. One patient with spondylitis had moderately severe (asymptomatic) proctitis, characterised by an acute inflammatory cell infiltration of the normal epithelium and occasional crypt abscesses. Another patient with spondylitis who was not taking drugs had moderately severe duodenitis, characterised by increased numbers of plasma cells and lymphocytes in the lamina propria and crypt lengthening. One patient with rheumatoid arthritis who was taking nonsteroidal antiinflammatory drugs and penicillamine had similar evidence of duodenitis. Separate analysis of these 3 patients confirmed that they did not significantly influence the remaining results.

The methyl green pyronine technique used on the rectal biopsies showed that the mean number of pyronine-positive cells per standard area of lamina propria did not differ significantly between diagnostic groups: spondylitis 762 , uveitis 702 , rheumatoid arthritis 690 , relatives 768 , irritable bowel syndrome 771.

In the immunoperoxidase studies of rectal biopsies the mean number of IgG-containing cells was significantly increased in patients with ankylosing spondylitis (Table 1, Fig. 1). When the numbers of IgGcontaining cells in patients with spondylitis, uveitis, rheumatoid arthritis, and irritable bowel syndrome were compared by the Kruskal-Wallis test,
IgG CONTAINING CELLS PER $0.45 \mathrm{~mm}^{2}$ OF LAMINA PROPRIA

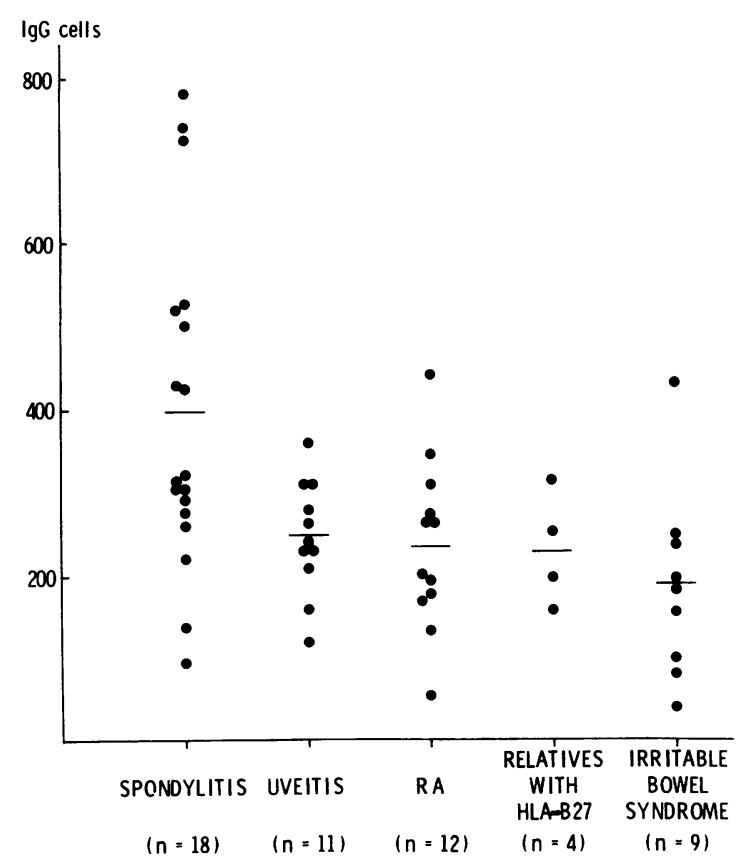

Fig. 1 Mean numbers of IgG containing cells per $0.45 \mathrm{~mm}$ of lamina propria in patients with spondylitis, uveitis, and rheumatoid arthritis, in relatives with $H L A-B 27$, and in controls (irritable bowel syndrome).

$\mathrm{p}<0 \cdot 001$. Spondylitis was then compared with irritable bowel syndrome: $p<0.005$ (Mann-Whitney $U$ test). When the mean number of IgG-containing cells was expressed as a ratio of the number of $\lg \mathrm{A}$ containing cells, the ratios for diagnostic groups were: spondylitis $0 \cdot 81$, uveitis $0 \cdot 70$, rheumatoid 
arthritis $0 \cdot 72$, relatives $0 \cdot 61$, and irritable bowel syndrome 0.45 ; spondylitis compared with irritable bowel syndrome (controls): $\mathrm{p}<0.01$ (Mann-Whitney $U$ test). The numbers of $\operatorname{IgA}, \operatorname{IgM}, \operatorname{IgD}$, and IgE cells did not differ significantly between the diagnostic groups. In individual patients there was no correlation between the numbers of rectal IgG cells and either the IgG concentration in the serum at the time of biopsy $(r=0 \cdot 37)$, age, sex, drug ingestion, disease activity, or the presence of peripheral arthritis.

The immunoperoxidase studies of duodenal biopsies showed no significant difference between diagnostic groups in the number of Ig-containing cells of any immunoglobulin class. The mean numbers of IgGcontaining cells in the duodenal biopsies were: spondylitis 78 , uveitis 144 , rheumatoid arthritis 111 , relatives 124 , and irritable bowel syndrome 116 . In no disease group was there a correlation in the individual patients between the numbers of Ig-containing cells in rectal and duodenal lamina propria for any of the immunoglobulin classes.

The rectal and duodenal biopsies studied by tissue immunofluorescence for chlamydiae and herpes simplex viruses were negative, and there was no evidence of any pathogenic organism at ultrastructural level. The other specimens collected in a search for evidence for infective agents also showed no significant abnormality.

\section{Discussion}

Despite the accepted association between ankylosing spondylitis and overt chronic inflammatory bowel disease the incidence of asymptomatic inflammation of the gut in patients with ankylosing spodylitis is small. Jayson and Bouchier ${ }^{5}$ investigated 33 patients with spondylitis and made a diagnosis of inflammatory bowel disease in 6: 3 were asymptomatic. Later Jayson et al. ${ }^{6}$ diagnosed inflammatory bowel disease in 8 out of 47 patients with spondylitis: 3 were asymptomatic. Meuwissen et al. ${ }^{7}$ studied 76 patients with spondylitis and no bowel symptoms: they found no imflammatory bowel disease. Costello et al. ${ }^{8}$ also found no bowel disease in 55 patients with spondylitis. In the present investigation one patient out of 18 with spondylitis had occult proctitis, but omission of his results did not influence the mean number of IgG-containing cells in the group of patients with spondylitis. The morphological features in the remaining patients with spondylitis did not differ from those seen in the other diagnostic groups. Moreover, independent assessment by the methyl green pyronine technique showed that the total numbers of pyronin-positive cells did not differ between the diagnostic groups.

The significant finding in the present investigation was an increase in the numbers of IgG-containing cells per unit area in the rectal lamina propria of patients with spondylitis but not in the duodenal lamina propria. Similar increases of IgG-containing cells in the rectal lamina propria have been reported in ulcerative colitis, both by immunofluorescence ${ }^{9}$ and by immunoperoxidase techniques,${ }^{10}$ and also in Crohn's disease affecting the rectum. ${ }^{10}$ Increased numbers of IgM-containing cells have been reported in the duodenal lamina propria in Crohn's disease. ${ }^{11}$ Rosenkrans et al. ${ }^{10}$ used the indirect immunoperoxidase technique and a similar quantitative method to that in the present study. They pointed out that counts of IgG-containing cells expressed per unit area of lamina propria may underestimate the degree of infiltration by such cells in inflammatory bowel disease, in which the true numbers of cells per millimetre of mucosal length may be increased either by greater thickness of the lamina propria or by loss of crypts. This possible source of error did not apply to our biopsy material.

It is open to speculation whether the increase of IgG-containing cells in the rectal lamina propria of patients with ankylosing spondylitis is: $(a)$ a local immunocyte reaction, possibly as a response to a local antigen in the large bowel, as has been postulated in chronic inflammatory bowel disease; $(b)$ a manifestation of an unidentified, more widespread immune reaction; or $(c)$ a forme fruste of chronic inflammatory bowel disease (not necessarily due to a local antigen, but conceivably reflecting the genetic links between spondylitis and chronic inflammatory bowel disease). Of the 3 possibilities the first seems to us to be the most likely - and potentially the most helpful. The main importance of the present study is probably in indicating rectal biopsy as a highly relevant (and readily accessible) source of tissue for further investigation by other techniques. So far the antibody specificity of the IgG produced by these cells in the rectal lamina propria is not known.

We thank many people who helped us, particularly the patients, the consultants, and casualty officers at Moorfields, Dr R. G. Bird, Professor S. Darougar, Dr J. D. Treharne, Mr T. Forsey, Professor J. R. Pattison, Dr R. Zeegen, and Dr B. G. Gazzard. Dr D. Timlin kindly advised on the statistical analysis.

This investigation was made possible by a grant from The Arthritis and Rheumatism Council.

\section{References}

1 Diagnostic Criteria: Ankylosing spondylitis. In: Bennett $\mathbf{P} \mathbf{H}$ Wood P H N, eds. Population studies of the rheumatic diseases. Proceedings of the 3rd International Symposium. New York 1966. Amsterdam: Excerpta Medica, 1968: 456-7.

2 Diagnostic Criteria: Rheumatoid arthritis. In: Bennett $\mathbf{P} \mathbf{H}$, Wood P H N, eds. Population studies of the rheumatic diseases. Proceedings of the 3rd International Symposium. New York 1966. Amsterdam: Excerpta Medica, 1968: 454-5. 
3 Burns J. Background staining and sensitivity of the unlabelled antibody-enzyme (PAP) method. Histochemistry 1975; 43: $291-4$

4 Stemberger L A. Immunocytochemistry. 2nd Ed. New York: Wiley, 1979: 54.

5 Jayson M I V, Bouchier I A D. Ulcerative colitis with ankylosing spondylitis. Ann Rheum Dis 1968; 27: 219-24.

6 Jayson M I V, Salmon P R, Harrison W J. Inflammatory bowel disease in ankylosing spondylitis. Gut 1970; 11: 506-11.

7 Meuwissen S G M, Dekker-Saeys B J, Agenant D, Tytgat G N J. Ankylosing spondylitis and inflammatory bowel disease. 1 . Prevalence of inflammatory bowel disease in patients suffering from ankylosing spondylitis. Ann Rheum Dis 1978; 37: 30-2.

8 Costello P B, Alea J A, Kennedy A C, McCluskey R T,
Green F A. Prevalence of occult inflammatory bowel disease in ankylosing spondylitis. Ann Rheum Dis 1980; 39: 453-6.

9 Brandtzaeg P, Baklien K, Fausa O, Hoel P S. Immunohistochemical characterisation of local immunoglobulin formation in ulcerative colitis. Gastroenterology 1974; 66: 1123-36.

10 Rosenkrans P C M, Meijer C J L M, Van Der Wal A M, Cornelisse $\mathrm{C} \mathrm{J}$, Lindeman J. Immunoglobulin containing cells in inflammatory bowel disease of the colon: a morphometric and immunohistochemical study. Gut 1980; 21: 941-7.

11 Van Spreeuwel J P, Lindeman J, Van Der Wal A M, Weterman I, Kreuning J, Meijer C J L M. Morphological and immunohistochemical findings in upper gastrointestinal biopsies of patients with Crohn's disease of the ileum and colon.J Clin Pathol 1982; 35: 934-40. 